\title{
A comparison of intrathecal magnesium and ketamine in attenuating remifentanil- induced hyperalgesia in rats
}

\author{
Jiehao Sun ${ }^{1}$, Hai Lin ${ }^{1,2}$, Xiaona Feng ${ }^{1}$, Jiaojiao Dong ${ }^{1}$, Emmanuel Ansong ${ }^{1}$ and Xuzhong Xu ${ }^{1 *}$
}

\begin{abstract}
Background: Activation of NMDA receptors play an important role in the development of remifentanil-induced hyperalgesia. We hypothesized that in addition to ketamine, intrathecal $\mathrm{MgSO}_{4}$ could also relieve thermal and mechanical hyperalgesia in rats.
\end{abstract}

Methods: Initially, 24 Sprague-Dawley rats were divided into control group, remifentanil group, surgical incision group and remifentanil combined with surgical incision group to create an experimental model. Subsequently, 40 rats were divided into control group, model group, model group plus $100 \mu \mathrm{g} \mathrm{MgSO}$, $300 \mu \mathrm{g} \mathrm{MgSO} \mathrm{H}_{4}$ and $10 \mu \mathrm{g}$ ketamine respectively. Paw withdrawal mechanical thresholds and paw withdrawal thermal latency tests were performed at $-24 h, 2 h, 6 h, 24 h, 48 h, 72 h$ and 7 day after the surgical procedure. After behavior assessment on the 7th day, remifentanil was given again to ascertain whether or not NMDA antagonists could suppress the reexposure of remifentanil-induced hyperalgesia.

Results: Remifentanil administration plus surgical incision induced significant postoperative hyperalgesia, as indicated by decreased paw withdrawal mechanical thresholds and paw withdrawal thermal latency to mechanical and thermal stimulation. In addition to ketamine, intrathecal $\mathrm{MgSO}_{4}(100,300 \mu \mathrm{g})$ dose-dependently reduced remifentanil-induced mechanical and thermal hyperalgesia. Ketamine had less mechanical hyperalgesia in $6 \mathrm{~h}$ $(p=0.018), 24 \mathrm{~h}(p=0.014)$ and $48 \mathrm{~h}(p=0.011)$ than $300 \mu \mathrm{g} \mathrm{MgSO}$. There was no difference in inhibiting thermal hyperalgesia between the group ketamine and group $\mathrm{MgSO}_{4}(300 \mu \mathrm{g})$. The rats were given remifentanil again 7 days later after the first exposure of remifentanil. The hyperalgesic effect induced by re-exposure of remifentanil was not reversed in any groups of $\mathrm{MgSO}_{4}$ or ketamine.

Conclusions: In addition to ketamine, intrathecal administration of $\mathrm{MgSO}_{4}$ dose-dependently reduced remifentanilinduced hyperalgesia in a surgical incision mode. Re-exposure to remifentanil 1 week later again produced hyperalgesia, and this was not altered by the prior intrathecal treatments in any 4 groups treated with $\mathrm{MgSO}_{4}$ or ketamine.

Keyword: Magnesium, Remifentanil, Hyperalgesia, Ketamine

Abbreviations: NMDA, N-methyl-D-aspartate; NRS, Numeric rating scale; OlH, Opioid-induced hyperalgesia; $\mathrm{RIH}$, Remifentanil-induced hyperalgesia; PWMT, Paw withdrawal mechanical thresholds; PWTL, Paw withdrawal thermal latency

\footnotetext{
* Correspondence: xuzhong@263.net

${ }^{1}$ Department of Anesthesiology, 1st Affiliated Hospital of Wenzhou Medical

University, 1\# shangcaicun, Wenzhou 325000, China

Full list of author information is available at the end of the article
} 


\section{Background}

Opioids are the standard of care in the treatment of postoperative pain. However, opioids are also associated with the development of paradoxical, pathologic pain that presents as hyperalgesia [1]. Opioid-induced hyperalgesia $(\mathrm{OIH})$ may counteract its own antinociceptive effect, as well as aggravating a pre-existing pain condition after surgery.

Due to its rapid clearance and recovery, remifentanil is frequently used for post-surgical pain and has more predictable therapeutic outcomes [2]. However, hyperalgesia occurs after a brief exposure to remifentanil and contributes to an increase in postoperative pain [3]. Remifentanil can induce latent pain sensitization [4] and can contribute to the transition from acute to chronic pain.

MK-801, a N-methyl-D-aspartate (NMDA) receptor antagonist, showed reversal effect of OIH [4]. Small doses of ketamine also reversed remifentanil induced hyperalgesia (RIH) [5]. However, side effect of ketamine limits its use in clinics. $\mathrm{MgSO}_{4}$ also has been proven to antagonize NMDA receptor and hence, it has analgesic effect. $\mathrm{MgSO}_{4}$ acts inside the NMDA receptor channel and occludes the $\mathrm{Ca}^{2+}$ current in neurons in the dorsal spinal cord, and hence decrease central release of glutamate [6]. Magnesium was reported to not only prevent the delayed and prolonged hyperalgesia [7, 8] but also to enhance the antinociceptive effect [2] of fentanyl administration in rats. Its effect on hyperalgesia could be regarded as similar to ketamine administration.

In the current study, we hypothesized that intrathecal (i.t.) $\mathrm{MgSO}_{4}$ could have equal effects in preventing $\mathrm{RIH}$ compared with ketamine. We would also test whether or not a single dose of a NMDA receptor antagonist could inhibit re-exposure of remifentanil administration 1 week later after the first remifentanil administration.

\section{Method}

\section{Animals}

The experimental protocol was approved by the Institutional Animal Care Committee, Wenzhou Medical University. Adult male Sprague-Dawley rats (280 \pm 330 g) had an acclimation period of at least 1 week. All animals were maintained at a constant temperature $\left(22 \pm 1{ }^{\circ} \mathrm{C}\right)$ with 12:12 h light: dark cycle.

\section{Intrathecal catheter placement}

Intrathecal catheters (PE-10 tube, OD: $0.5 \mathrm{~mm}$, ID: $0.25 \mathrm{~mm}$, AniLab Co. Ltd, China) were implanted under sevoflurane anesthesia using the method described by Liu [9] with some modifications. We have not cut the partial process of L3 in order to decrease the injury to rats.

\section{Surgical incision}

Surgical incision was performed under sevoflurane anesthesia using the method described by Brennan [10]. A longitudinal incision was made from the proximal edge of the heel extending toward the toes in the right hind paw. The plantaris muscle was elevated by forceps, leaving the muscle origin and insertion intact. After homostasis, the skin was closed and covered with antiseptic gauze.

To decrease individual error, catheters implantation and surgical incision were performed by Sun and Feng respectively.

Remifentanil was dissolved in normal saline and infused i.v. at a rate of $1.2 \mu \mathrm{g} . \mathrm{kg}-1 . \mathrm{min}-1$ for $60 \mathrm{~min}$.

\section{Pain assay}

Mechanical allodynia was evaluated by electronic von Frey anesthesiometer (IITC INC, Life Science instrument, CA, USA). The pressure value was recorded as paw withdrawal mechanical thresholds (PWMT) by transducer (ALMEMO 2450, Ahlborn, Germany). Animals were placed in individual wire cages $(20 \times 14 \times 20 \mathrm{~cm})$ with a mesh bottom $(1 \times 1 \mathrm{~cm})$ and allowed to acclimatize for $30 \mathrm{~min}$ before testing. A $0.8-\mathrm{mm}$ diameter straight filament was used to apply a force to the plantar surface of the right hind paw. Paw withdrawal or licking was considered nociceptive-like responses. The test was repeated 3 times with an interval of $5 \mathrm{~min}$. The mean PWMT was obtained from the average value of the 3 trials.

To evaluate thermal hyperalgesia, paw withdrawal thermal latency (PWTL) was measured by testing equipment (Model 336, Series 8, IITC INC, Life Science instrument, CA, USA). Rats were placed in a clear plastic chamber $(22 \mathrm{~cm} \times 12 \mathrm{~cm} \times 12 \mathrm{~cm}$ ) with a glass floor (5 mm thick) and allowed to acclimatize for $30 \mathrm{~min}$ before testing. A radiant heat source was positioned under the glass floor and focused on the plantar surface adjacent to the wound of right hind paw. PWTL was measured by recording the time from the onset of heat stimulus to withdrawal of the hind paw. A cutoff time of $25 \mathrm{~s}$ was established to prevent tissue damage. The test was repeated 3 times with an interval of $5 \mathrm{~min}$. The mean PWL was obtained from the average value of the 3 trials.

\section{Drugs preparation}

The following drugs were used: remifentanil hydrochloride (Ultiva) (batch number: 6150406, Ren Fu Co, China), ketamine hydrochloride (1504151, Heng Rui Co, China), Magnesium sulfate (M2643, Sigma. St. Louis, USA), sevoflurane (4Z121, maruishi-pharm.co. Japan).

\section{Experiment protocol}

All of the following experiments were carried out 7 days later after intrathecal catheter implantation. 
Experiment 1

This experiment comprised four groups of rats $(n=6)$ : group $\mathrm{C}$ (rats underwent a sham procedure that consisted of the sevoflurane anesthesia and the same volume of saline without incision); group I (rats underwent a surgical incision and the same volume of saline); group R (rats underwent remifentanil infusion without surgical incision); and group RI (rats underwent surgical incision with remifentanil infusion). PWMT and PWTL tests were performed at $-24 \mathrm{~h}, 2 \mathrm{~h}, 6 \mathrm{~h}, 24 \mathrm{~h}, 48 \mathrm{~h}$ and $72 \mathrm{~h}$ after the surgical incision.

Experiment 2

This experiment consisted of five groups of rats $(n=8)$ : group $C$ (rats underwent a sham procedure that consisted of the sevoflurane anesthesia and the same volume of saline without incision); group RI (rats underwent surgical incision with remifentanil infusion); group RIK (i.t. $10 \mu \mathrm{g}$ ketamine was given to the group RI); group $\mathrm{RIM}_{\text {low }}$ (i.t. $100 \mu \mathrm{g} \mathrm{MgSO}_{4}$ was given to the group RI); group $\mathrm{RIM}_{\text {high }}$ (i.t. $300 \mu \mathrm{g} \mathrm{MgSO}_{4}$ was given to the group RI). Ketamine, $\mathrm{MgSO}_{4}$ and normal saline were injected in a volume of $10 \mu \mathrm{l}$ using a microinjection syringe $30 \mathrm{~min}$ before plantar incision. An additional of $20 \mu \mathrm{l}$ normal saline was administered to flush the catheter. After the injection, the end of the catheter was plugged. PWMT and PWTL tests were performed at $-24 \mathrm{~h}$, $2 \mathrm{~h}, 6 \mathrm{~h}, 24 \mathrm{~h}, 48 \mathrm{~h}, 72 \mathrm{~h}$ and 7 days after the surgical procedure.

On day 7 following behavioral assessments, remifentanil was administered again at a rate of $1.2 \mu$ g.kg-1.min-1 for $60 \mathrm{~min}$, similar with the first exposure of remifentanil. Behavior assessment was performed $6 \mathrm{~h}$ after the reexposure of remifentanil.

\section{Statistical analysis}

The primary outcome was the AUC value of mechanical hyperalgesia (0-48 h) after surgical incision and remifentanil infusion. We found that a sample size of 7 rats per group would achieve $80 \%$ power to detect a $20 \%$ reduction in AUC value using one-way ANOVA. Assuming a $10 \%$ drop rate, we recruited 8 rats to each group.

All data are expressed as mean \pm SD. Time course data for behavioral tests were performed by repeated measures ANOVA. The AUC value of hyperalgesia were statistically tested by ANOVA test with Bonferroni test as post hoc test. Probability values less than 0.05 were considered significant. Sample size estimates were done using PASS software (PASS 2008, Kaysville, UT, USA). Statistical analyses were done using SPSS 15.0 software (SPSS Inc., Chicago, IL, USA).

\section{Result}

No statistically significant differences were detected between the basal PWMT and PWTL tests of each experimental group $(p>0.05)$.

\section{RIH model}

Repeated measures ANOVA revealed Group RI induced more severe thermal hyperalgesia $\left(\mathrm{F}_{(3,95)}=350.641\right.$, $p<0.01)$ and an interaction between thermal hyperalgesia and time $\left(\mathrm{F}_{(15,95)}=3.041, p<0.001\right)$. Group RI also had more severe mechanical hyperalgesia $\left(\mathrm{F}_{(3,95)}=464.358\right.$, $p<0.01)$ and an interaction between thermal hyperalgesia and time $\left(\mathrm{F}_{(15,95)}=2.854, p<0.001\right)$. Group $\mathrm{R}$ induced more severe thermal hyperalgesia effect in $6 \mathrm{~h}(p=0.019)$ and $24 \mathrm{~h}(p=0.03)$ than Group I. (Fig. 1).

\section{The effect of NMDA antagonists on RIH}

$\mathrm{RIH}$ was dose-dependently depressed by $\mathrm{MgSO}_{4}(100$, $300 \mu \mathrm{g})$. The treatment with $300 \mu \mathrm{g} \mathrm{MgSO}_{4}$ also significantly suppressed remifentanil-induced thermal hyperalgesia, although it was not statistically different from ketamine treatment. Ketamine had less mechanical hyperalgesia in $6 \mathrm{~h}(p=0.018), 24 \mathrm{~h}(p=0.014)$ and $48 \mathrm{~h}$ $(p=0.011)$ than $300 \mu \mathrm{g} \mathrm{MgSO}_{4}$ (Fig. 2).

As shown in Table 1, the AUC for thermal hyperalgesia was lower in the group RIM $_{\text {low }}$ compared with the group RI. The AUC for thermal hyperalgesia was lower in group RIK, group RIM $_{\text {high }}$ compared with the other three groups at $0-24 \mathrm{~h}, 0-48 \mathrm{~h}$ and $48-72 \mathrm{~h}(P<0.001)$. There was no statistical difference in group RIK and group RIM high.

As shown in Table 1, the AUC for mechanical hyperalgesia was dose-dependently lower in group RIM $_{\text {high }}$ and group RIM low compared with group RI. Group RIK had the lowest AUC of mechanical hyperalgesia. Group RIK had lower AUC of 0 - 48 h compared with group $\operatorname{RIM}_{\text {high }}(P=0.002)$.

\section{The re-exposure of remifentanil}

Re-exposure to remifentanil resulted in hyperalgesia at 7 days and was not altered by $\mathrm{MgSO}_{4}$ or ketamine we gave 7 days before (Fig. 2).

\section{Discussion}

The current study indicated that RIH began from 2nd hour and peaked at 48th hour after remifentanil infusion. Behavioral assessments in current study suggested that thermal hyperalgesia induced by remifentanil was even greater than surgery induced during $24 \mathrm{~h}$ after the test, the same with report by Zhang et al. [11].

In order to distinguish RIH from tissue injury of noxious stimulus, we performed the classical rat plantar incision pain model to explore RIH [10]. We selected sevoflurane for anesthesia because it was previously 

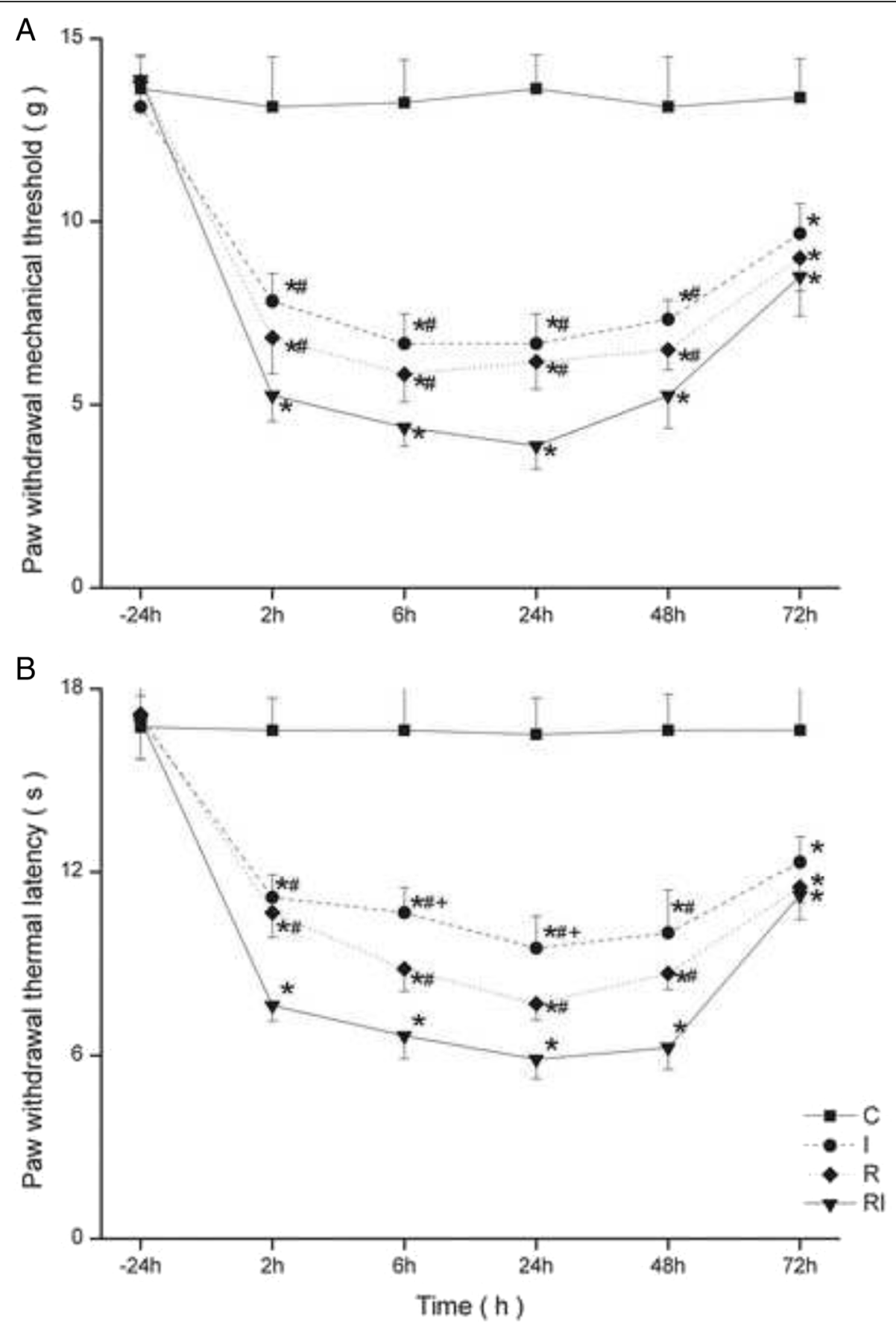

Fig. 1 a-b Paw withdrawal mechanical threshold (a) and paw withdrawal thermal latency (b) were evaluated at 24 h before incision and 2, 6, 24, 48 and 72 h after remifentanil infusion. Groups allocation: R: Group remifentanil; Rl: Group remifentanil + surgical incision; C: Group Control; l: Group surgical incision. Data are expressed as means \pm SD. * $P<0.001$ compared with Group $C$, $\# P<0.001$ compared with Group Rl, $+P<0.05$ compared with Group R

proved to have no influence on nociceptive thresholds [12]. What is the relationship between RIH and opioid receptors for remifentanil? It was reported that blockage of the $\mu[13], \delta[14]$, or $\mathrm{k}$ receptor [4] could precipitates OIH. However, opioids [15] could also cause hyperalgesia in triple knock-out mice which was completely devoid of $\mu, \delta$ and $\mathrm{k}$ opioid receptors [16]. In other words, RIH in rats is not dependent on opioid receptor activity [17].

The mechanism underlying RIH remains controversial. Induced-NMDA current can be potentiated by the application of remifentanil in an in vitro study [18]. By using 

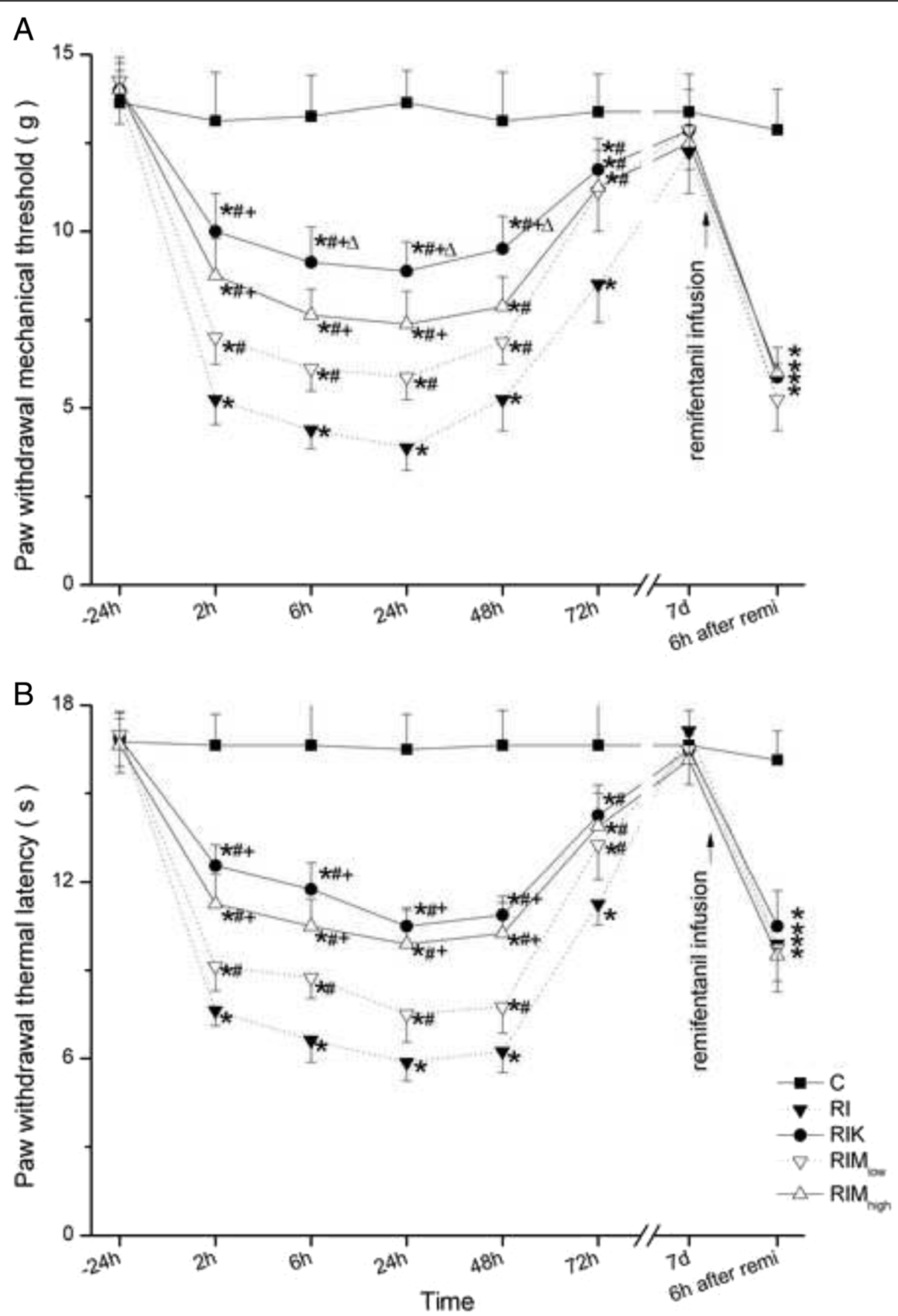

Fig. 2 a-b The NMDA antagonist ketamine and $\mathrm{MgSO}_{4}$ were administered intrathecally 30 min before remifentanil infusion and surgical incision. Paw withdrawal mechanical threshold (a) and paw withdrawal thermal latency (b) were evaluated at $24 \mathrm{~h}$ before incision and 2, 6, 24, 48, 72 h, 7 days after remifentanil infusion, $6 \mathrm{~h}$ after re-exposure of remifentanil 7 days later. Groups allocation: Rl: Group remifentanil + surgical incision; C: Group Control; RIK: Group i.t. $10 \mu \mathrm{g}$ ketamine was given to the group RI; RIMlow: Group i.t. $100 \mu \mathrm{g} \mathrm{MgSO} 4$ was given to the group Rl; RIM high: Group i.t. $300 \mu \mathrm{g} \mathrm{MgSO}_{4}$ was given to the group RI. Data are expressed as means $\pm \mathrm{SD}$. ${ }^{*} P<0.001$ compared with Group $C$, \# $P<0.001$ compared with Group RI, $+P<0.01$ compared with Group RIM low, $_{\Delta} P<0.05$ compared with Group RIM high

a two-electrode voltage clamp, remifentanil was found to directly stimulate NMDA receptors of different subunit combinations $\left(\mathrm{NR}_{1} \mathrm{~A} /{ }_{2} \mathrm{~A}, \mathrm{NR}_{1} \mathrm{~A} /{ }_{2} \mathrm{~B}\right)$ in Xenopus laevis oocytes [19]. However, remifentanil itself was not able to stimulate NMDA receptors in spinal cord [20]. Up-regulation of NMDA receptor functions induced by remifentanil may contribute to the clinical development of RIH. It was suggested that enhancing NMDA receptor 
Table 1 AUC value of NRS scores for thermal and mechanical hyperalgesia

\begin{tabular}{|c|c|c|c|c|c|}
\hline & Group C & Group RI & Group RIMlow & Group RIM high & Group RIK \\
\hline \multicolumn{6}{|c|}{ Thermal hyperalgesia } \\
\hline$A \cup C_{T 0-24 ~ h}$ & $431.3 \pm 32.4$ & $179.9 \pm 12.1^{*}$ & $226.0 \pm 11.4^{* * *}$ & $276.5 \pm 18.0^{*}, * * * * * *$ & $301.4 \pm 12.5^{*}, *^{* *}, * * *$ \\
\hline $\mathrm{A} \cup \mathrm{C}_{\mathrm{TO}-48 \mathrm{~h}}$ & $828.8 \pm 60.4$ & $325.4 \pm 24.7^{*}$ & $409.0 \pm 21.1^{*}, * *$ & $518.0 \pm 35.8^{*}, * *, * * *$ & $557.9 \pm 18.8^{*}, * * *^{* * *}$ \\
\hline$A \cup C_{T 48-72 h}$ & $399.0 \pm 30.6$ & $210.0 \pm 11.1^{*}$ & $252.0 \pm 12.8^{*}, * *$ & $289.5 \pm 18.6^{*},{ }^{* *},{ }^{* * *}$ & $301.5 \pm 15.0^{*}, * *, * * *$ \\
\hline \multicolumn{6}{|c|}{ Mechanical hyperalgesia } \\
\hline$A \cup C_{M 0-24 h}$ & $338.8 \pm 27.2$ & $133.5 \pm 31.6^{*}$ & $170.9 \pm 11.2^{*}$ & $204.6 \pm 16.5^{* * *}$ & $238.9 \pm 25.7^{*}, * * * * * *$ \\
\hline$A \cup C_{M O-48 ~ h}$ & $659.8 \pm 42.5$ & $243.0 \pm 40.2^{*}$ & $323.9 \pm 15.6^{*}, * *$ & $387.6 \pm 25.7^{*}, *^{* *}, * * *$ & $459.4 \pm 39.3^{*}, * * * * * * * * * *$ \\
\hline$A \cup C_{M 48-72 h}$ & $318.0 \pm 28.7$ & $165.0 \pm 20.0^{*}$ & $216.0 \pm 12.8^{*}, * *$ & $229.5 \pm 15.0^{*}, * *$ & $255.0 \pm 15.4^{*}, * *, * * *$ \\
\hline
\end{tabular}

Data are mean \pm SD. AUC Area under the curve

Groups allocation: $R I$ Group remifentanil + surgical incision, C Group Control, RIK Group intrathecal $10 \mu g$ ketamine, RIMlow Group intrathecal $100 \mu g$ MgSO4, RIM high Group intrathecal $300 \mu \mathrm{g} \mathrm{MgSO} 4$

*: $P<0.001$ vs group $C_{;}{ }^{* *}: P<0.001$ vs group $\mathrm{Rl}^{*}{ }^{* * *}: P<0.01$ vs group $\mathrm{RIM}_{\text {low }}$

**** $P<0.01$ vs group RIM high

activity via an intracellular pathway can increase the amount of glutamate [21]. Activation of NMDA receptors could lead to $\mathrm{Ca}^{2+}$ entry into the cell, which resulted in a further release of glutamate and more propagation of the pain signal to the brain [20]. NMDA receptor mediated neurotoxicity and apoptosis in the dorsal horn was also involved in RIH after opioid administration [22].

Although $\mathrm{MgSO}_{4}$ is weak in antagonizing the NMDA receptor, the results demonstrate that $300 \mu \mathrm{g} \mathrm{MgSO}_{4}$ has equal effect compared with $10 \mu \mathrm{g}$ ketamine in suppressing thermal hyperalgesia induced by remifentanil administration. For mechanical hyperalgesia, $300 \mu \mathrm{g}$ $\mathrm{MgSO}_{4}$ was not as effective as ketamine.

Mechanical allodynia and thermal hyperalgesia are neurochemically distinct, particularly in relation to the involvement of the NMDA receptor [23]. Thus, NMDA receptor antagonists are more efficacious in reducing mechanical than thermal hyperalgesia in persistent inflammation, and suggesting that mechanical hyperalgesia is mediated through spinal dorsal horn NMDA receptors [24]. In the present study, $\mathrm{MgSO}_{4}$ was more effective in inhibiting thermal hyperalgesia, consistent with the results from a previous study [25]. Perhaps NMDA antagonists had a differential susceptibility to express opioidassociated hyperalgesia.

Subcutaneous ketamine did not significantly modify the early analgesic component, but almost completely prevented the delayed decrease in nociceptive threshold after opioid administration [26]. However, the clinical application of ketamine to prevent hyperalgesia is limited because of side effects such as somnolence, dizziness and sedation [27].

Intrathecal administration of $\mathrm{MgSO}_{4}$ may be clinically applicable in patients with fentanyl infusion hyperalgesia [28]. Since $\mathrm{MgSO}_{4}$ cannot pass through the blood brain barrier due to its high polarity, intrathecal administration can increase $\mathrm{Mg}^{2+}$ concentration in the central nervous system with less systemic effect. Intrathecal $\mathrm{Mg}^{2+}$ (100 to $500 \mu \mathrm{g})$ produced a dose-dependent antinociceptive effect against formalin stimulus [28]. Intrathecal injection of $500 \mu \mathrm{g} \mathrm{MgSO}_{4}$ produced lethargy and slight ataxia, and these symptoms were more pronounced in the rats receiving $750 \mu \mathrm{g}$ or more $[26,28]$. It was reported that $300 \mu \mathrm{g}$ $\mathrm{MgSO}_{4}$ had no motor effects. While intrathecal $\mathrm{Mg}^{2+}$ $(20 \mu \mathrm{g})$ was proved to have no antiallodynic effects [29]. Therefore, the doses of $100 \mu \mathrm{g}, 300 \mu \mathrm{g}$ and $500 \mu \mathrm{g}$ of $\mathrm{MgSO}_{4}$ were employed in the dose-response analysis in pre-test. 3 of the 4 rats were found to exhibit flaccid paresis in the group which had a dose of $500 \mu \mathrm{g} \mathrm{MgSO}_{4}$ in the pretrial, so we excluded this dose.

It was reported that $10 \mu \mathrm{g}$ i.t. ketamine intrathecally had no effect on postoperative analgesia [27]. Rota rod test revealed that motor dysfunction was found with the use of i.t. ketamine at doses above $10 \mu \mathrm{g}$ [27]. So the dose of $10 \mu \mathrm{g}$ ketamine was selected for use in the current trial.

Some studies have demonstrated that remifentanil can trigger postoperative secondary hyperalgesia $[5,30]$. Thus, rats with previous exposure to remifentanil several months earlier exhibit even more severe hyperalgesia after second remifentanil administration [4, 31]. NMDA antagonists was showed to modulate the pre-emptive analgesic efficacy. Epidural infusion of ketamine before transabdominal hysterectomy was reported to reduce pain scores for 2 days after surgery [32]. Pre-emptive treatment with NMDA receptor antagonists cause a lasting change in spinal NMDA receptor complexes which should be more effectively targeted by NMDA receptor antagonists again [33]. In the current trial, We expected to see the anti-nociceptive effect if the intrathecal pretreatment of NMDA antagonists had blocked the hyperalgesia earlier. However, the study found that the NMDA antagonists given 7 days before did not inhibit 
hyperalgesia induced by re-exposure to remifentanil. Although re-exposure to remifentanil was able to induce hyperalgesia in the present trial, we did not observe that hyperalgesia induced by re-exposure of remifentanil was more severe than the first exposure. It might be attributed to the shorter interval period between the first and second remifentanil administration compared with previous report $[4,31]$. In clinics, some operations require multiple sessions. It is common to find patients operated on again 1 week after a first operation. Some patients need to perform emergent traumatic operation first to correct severe physiological status several days before, following by a second operation later. This is the reason the remifentanil re-infusion was made after 7 days in this trial.

\section{Limitations}

1: In this trial, $\mathrm{MgSO}_{4}$ was given before remifentanil administration. It has been reported that the ability of $\mathrm{MgSO}_{4}$ to suppress hyperalgesia before NMDA activation was lesser from that of the potency after NMDA activation [28]. We did not have the group in which $\mathrm{MgSO}_{4}$ was given after remifentanil administration to prove that $\mathrm{MgSO}_{4}$ administration before/after remifentanil infusion have different effect of inhibiting RIH. 2: Before we made assessment of re-exposure to remifentanilinduced hyperalgesia, we did not give any additional NMDA receptor antagonist. We postulated that ketamine or $\mathrm{MgSO}_{4}$ given 7 days before could still have effect to inhibit RIH but could not be demonstrated in current trial. Further study should aim to investigate whether an intermittent or a continuous exposure to NMDA antagonist will be effective in inhibiting RIH after a second exposure to remifentanil. 3: Many studies have shown that the distribution of $\mathrm{NR}_{2} \mathrm{~B}$ subunit in NMDA receptor is limited to the superficial dorsal horn of lumbar spinal cord [11, 14]. The phosphorylation of $\mathrm{NR}_{2} \mathrm{~B}$ subunit is related to activation of $\mathrm{RIH}$ process. Due to inadequate funding, we did not make western blots to detect the amount of phosphorylation in $\mathrm{NR}_{2} \mathrm{~B}$ subunit after $\mathrm{MgSO}_{4}$ administration.

\section{Conclusion}

To the best of our knowledge, this is the first demonstration that intrathecal administration of $\mathrm{MgSO}_{4}$ and ketamine can suppress RIH. While NMDA receptor antagonists inhibit RIH when given acutely (i.e. on the day of treatment), they do not have a pre-emptive effect to block hyperalgesia resulting from re-exposure to remifentanil 1 week later. Maybe there was no longer any NMDA antagonists available to block the NMDA receptor then. Future studies will need to address the usage or application of $\mathrm{MgSO}_{4}$ in a multimodal peri-operative analgesic management targeting the prevention of $\mathrm{RIH}$ in clinics.

\section{Additional file}

Additional file 1: Supplementary material. (XLSX $13 \mathrm{~kb})$

\section{Acknowledgements}

We would like to thank Ruichen Shu from Tianjin Medical University for technical assistance and statistical preparation. We should also thank the staff in the writing center of Ohio State University of USA for assistance in manuscript preparation.

\section{Funding}

The authors received the funding from the program of Wenzhou science and technology bureau [Y20140698] and the program of international clinical exchange of Zhejiang province [Zhejiang Health 2013-197].

Availability of data and materials

All data generated or analysed during this study are included in this published article (Additional file 1).

\section{Authors' contributions}

JS. Contribution: Design the trial, acquisition of data, data analysis and give interpretation of data. HL. Contribution: Design the trial, data analysis and give interpretation of data. XF. Contribution: Design the trial, acquisition of data. JD. Contribution: Design the trial, acquisition of data. EAg. Contribution: Revise the paper critically for important intellectual content. XX. Contribution: Design the trial, analysis and give interpretation of data. He also gave final approval of the version to be published. All authors read and approved the final manuscript.

\section{Competing interests}

The authors declare that they have no competing interests.

\section{Consent for publication}

Not applicable.

\section{Ethics approval and consent to participate}

The experimental protocol was approved by the Institutional Animal Care Committee, Wenzhou Medical University.

\section{Author details}

${ }^{1}$ Department of Anesthesiology, 1st Affiliated Hospital of Wenzhou Medical University, 1\# shangcaicun, Wenzhou 325000, China. ${ }^{2}$ Department of Anesthesiology and Pain medicine, 1st Affiliated Hospital of Wenzhou Medical University, Wenzhou, China.

Received: 21 January 2016 Accepted: 24 August 2016

Published online: 06 September 2016

\section{References}

1. Fletcher D, Martinez V. Opioid-induced hyperalgesia in patients after surgery: a systematic review and a meta-analysis. Brit J Anaesth. 2014;112:991-1004.

2. Derrode N, Lebrun F, Levron JC, Chauvin M, Debaene B. Influence of perioperative opioid on postoperative pain after major abdominal surgery: sufentanil TCl versus remifentanil TCI. A randomized, controlled study. Brit J Anaesth. 2003;91:842-9.

3. Shin SW, Cho AR, Lee HJ, et al. Maintenance anaesthetics during remifentanilbased anaesthesia might affect postoperative pain control after breast cancer. Brit J Anaesth. 2010;105:661-7.

4. Ana C, David C, Asunción R, Paula GN, Margarita MP. Delayed postoperative latent pain sensitization revealed by the systemic administration of opioid antagonists in mice. Eur J Pharmacol. 2011;657:89-96.

5. Joly $V$, Richebe $P$, Guignard B, et al. Remifentanil-induced postoperative hyperalgesia and its prevention with small-dose ketamine. Anesthesiology. 2005;103:147-55.

6. Chen L, Huang LY. Protein kinase C reduces $\mathrm{Mg}^{2+}$ block of NMDA receptor channels as a mechanism of modulation. Nature. 1992;9:521-3.

7. Alain C, Van E, Philippe S, Mazoit JX, Marc C, Dan B. Protective effect of prior administration of magnesium on delayed hyperalgesia induced by fentanyl in rats. Can J Anesth. 2006;53:1180-5. 
8. Tufan M, Yasemin G, Dilek O, Ismail G. Magnesium modifies fentanylinduced local antinociception and hyperalgesia. N-S Arch Pharmacol. 2009;380:415-20.

9. Liu X, Zhang J, Zhao H, Mei H, Lian Q, ShangGuan W. The effect of propofol on intrathecal morphine-induced pruritus and its mechanism. Anesth Analg 2014;118:303-9.

10. Brennan TJ, Vandermeulen EP, Gebhart GF. Characterization of a rat model of incisional pain. Pain. 1996;64:493-501.

11. Zhang $L$, Shu R, Wang $H$, et al. Hydrogen-rich saline prevents remifentanil induced hyperalgesia and inhibits MnSOD nitration via regulation of NR2Bcontaining NMDA receptor in rats. Neuroscience. 2014;280:171-80.

12. Célérier E, González JR, Maldonado R, Cabalvro D, Puig MM. Opioid-induced hyperalgesia in a murine model of postoperative pain: role of nitric oxide generated from the inducible nitric oxide synthase. Anesthesiology. 2006:104:546-55.

13. Célérier E, Laulin JP, Corcuff JB, Le Moal M, Simonnet G. Progressive enhancement of delayed hyperalgesia induced by repeated heroin administration: a sensitization process. J Neurosci. 2001;21:4074-80.

14. Wang C, Li Y, Wang H, et al. Inhibition of DOR prevents remifentanil induced postoperative hyperalgesia through regulating the trafficking and function of spinal NMDA receptors in vivo and in vitro. Brain Res Bull. 2015;110:30-9.

15. Juni A, Klein G, Pintar JE, Kest B. Nociception increases during opioid infusion in opioid receptor triple knock-out mice. Neuroscience. 2007;147:439-44.

16. Waxman AR, Arout C, Caldwell M, Dahan A, Kest B. Acute and chronic fentanyl administration causes hyperalgesia independently of opioid receptor activity in mice. Neurosci Lett. 2009;46:68-72.

17. Van Dorp EL, Kest B, Kowalczyk WJ, et al. Morphine-6- $\beta$-glucuronide rapidly increases pain sensitivity independently of opioid receptor activity in mice and humans. Anesthesiology. 2009;110:1356-63.

18. Li Y, Wang $H$, Xie $K$, et al. Inhibition of glycogen synthase kinase-3 $\beta$ prevents remifentanil-induced hyperalgesia via regulating the expression and function of spinal N-methyl-D-aspartate receptors in vivo and vitro. PLoS One. 2013;8:e77790.

19. Hahnenkamp K, Nollet J, Van Aken HK, et al. Remifentanil directly activates human N-methyl-D-aspartate receptors expressed in Xenopus laevis oocytes. Anesthesiology. 2004;100:1531-7.

20. Guntz E, Dumont $\mathrm{H}$, Roussel $\mathrm{C}$, et al. Effects of remifentanil on $\mathrm{N}$-methyl-daspartate receptor: an electrophysiologic study in rat spinal cord. Anesthesiology. 2005;102:1235-41.

21. Celerier E, Simonnet G, Maldonado R. Prevention of fentanyl-induced delayed pronociceptive effects in mice lacking the protein kinase $\mathrm{C}$ gene. Neuropharmacology. 2004;46:264-72.

22. Ram KC, Eisenberg E, Haddad M, Pud D. Oral opioid use alters DNIC but not cold pain perception in patients with chronic pain - new perspective of opioid- induced hyperalgesia. Pain. 2008;139:431-8.

23. Bennett AD, Everhart AW, Hulsebosch CE. Intrathecal administration of an NMDA or a non-NMDA receptor antagonist reduces mechanical but not thermal allodynia in a rodent model of chronic central pain after spinal cord injury. Brain Res. 2000;859:72-82.

24. Hama A, Jeung Woon $L$, Jacqueline S. Differential efficacy of intrathecal NMDA receptor antagonists on inflammatory mechanical and thermal hyperalgesia in rats. Eur J Pharmacol. 2003;459:49-58.

25. Xiao WH, Bennett GJ. Magnesium suppresses neuropathic pain response in rats via a spinal site of action. Brain Res. 1994:666:168-72.

26. Van Elstraete AC, Sitbon P, Trabold F, Mazoti JX, Benhamou D. A single dose of intrathecal morphine in rat induces long-lasting hyperalgesia: the protective effect of prior administration of ketamine. Anesth Analg. 2005;101:1750-6.

27. Lim HS, Kim JM, Choi JG, et al. Intrathecal ketamine and pregabalin at subeffective doses synergistically reduces neuropathic pain without motor dysfunction in mice. Biol Pharm Bull. 2013;36:125-30.

28. Yoshito T, Eiru S, Toshihiko K, Isao S. Antihyperalgesic effects of intrathecally administered magnesium sulfate in rats. Pain. 2000:84:175-9.

29. Cheng JK, Lai YJ, Chen CC, Cheng CR, Chiou LC. Magnesium chloride and rutbenium red attenuated the antialldodynic effect of intrathecal gabapentin in a rat model of postoperative pain. Anesthesiology. 2003:98:1472-9.

30. Echevarria G, Elgueta F, Fierro C, et al. Nitrous oxide (N2O) reduces postoperative opioid-induced hyperalgesia after remifentanil propofol anaesthesia in humans. Brit J Anaesth. 2011;107:959-65.
31. Cabañero D, Campillo A, Célérier E, Romero A, Puig MM. Pronociceptive effects of remifentanil in a mouse model of postsurgical pain: effect of a second surgery. Anesthesiology. 2009;111:1334-45.

32. Chen JQ, Wu Z, Wen LY, Miao JZ, Hu YM, Xue R. Preoperative and postoperative analgesic techniques in the treatment of patients undergoing transabdominal hysterectomy: a preliminary randomized trial. BMC Anesthesiol. 2015;15:70.

33. Wilson JA, Garry EM, Anderson HA, et al. NMDA receptor antagonist treatment at the time of nerve injury prevents injury-induced changes in spinal NR1 and NR2B subunit expression and increases the sensitivity of residual pain behaviours to subsequently administered NMDA receptor antagonists. Pain. 2005;117:421-32.

\section{Submit your next manuscript to BioMed Central and we will help you at every step:}

- We accept pre-submission inquiries

- Our selector tool helps you to find the most relevant journal

- We provide round the clock customer support

- Convenient online submission

- Thorough peer review

- Inclusion in PubMed and all major indexing services

- Maximum visibility for your research

Submit your manuscript at www.biomedcentral.com/submit

) BioMed Central 